\title{
Trade-offs between sampling effort and data quality in habitat monitoring
}

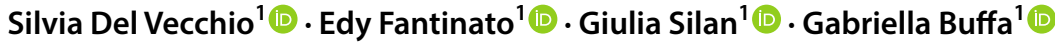

Received: 8 March 2018 / Revised: 10 September 2018 / Accepted: 24 September 2018

(c) Springer Nature B.V. 2018

\begin{abstract}
The transect method has been widely used to monitor habitat conservation status and has been recently recommended as the best tool to monitor steep ecological gradients, such as those in coastal systems. Despite that, the effectiveness of the transect approach can be limited when considering the sampling effort in terms of time needed for sampling. Our work aimed at evaluating the efficacy of the transect approach in a Mediterranean coastal system. Specifically we aimed at evaluating the sampling effort versus the completeness of datasets obtained by performing belt transects in different ways specifically designed to progressively reduce the sampling effort: (i) sampling plots adjacently ("adjacent-plot transect”); (ii) sampling plots alternately ("alternate-plot transect"); (iii) sampling one plot at each plant community along the vegetation zonation ("zonation-plot transect”). We evaluated method efficiency in terms of number and type of habitats identified, spatial extent, species richness and composition, through multivariate analyses, null models and rarefaction curves. The sampling effort was measured in terms of time needed for sampling. The zonation-plot transect had the lowest sampling effort, but provided only an approximation of the state of the dunal communities. The alternate-plot transect showed the best trade-off between the sampling effort and the completeness of information obtained, and may be considered as a efficient option in very wide coastal systems. Our research provides guidelines that can be used in other coastal systems to choose the most cost-effective monitoring method thereby maximising the efficient use of monitoring resources.
\end{abstract}

Keywords Coastal sand dunes $\cdot$ Habitat risk assessment $\cdot$ Data collection $\cdot$ Sampling efficiency $\cdot$ Belt transect

Communicated by Daniel Sanchez Mata.

This article belongs to the Topical Collection:Biodiversity protection and reserves.

Electronic supplementary material The online version of this article (https://doi.org/10.1007/s1053 1-018-1636-5) contains supplementary material, which is available to authorized users.

Silvia Del Vecchio

silvia.delvecchio@unive.it

1 Ca' Foscari University of Venice, Via Torino 155, 30172 Venice, Italy 


\section{Introduction}

The protection of species and habitats is an important challenge for biodiversity conservation. At European level, under Community law (Habitat Directive 92/43/EEC), Member States are required to provide a precise analysis of the conservation status of species and habitat types listed in the Habitat Directive and a regular monitoring and assessment of their trends (Evans and Arvela 2011).

Monitoring consists of regular field-based measurements of key indicators (e.g. population status and dynamics, species richness and composition), which are assumed to reliably convey the conservation status and trends of species and habitats (Lindenmayer and Likens 2010). Consistent estimate of a system state as well as robust projections of future trends depend on reliable science-based monitoring programs (Henle et al. 2013) and on the quality of input data (Meyer et al. 2016; Hughes et al. 2017). In particular, long term monitoring and detailed chronosequences better inform habitat conservation status and trends (Del Vecchio et al. 2015; Geri et al. 2016; Sperandii et al. 2018). On the other hand, since such detailed data usually require demanding and expensive surveys, monitoring is often criticized as being costly, wasteful, and unscientific (Lovett et al. 2007; Conn et al. 2016). To find a balance between the reliability of the monitoring program and its cost, efficient monitoring programs have to be based on a trade-off between the quality of data and the sampling effort, in terms of both costs and time (McDonald-Madden et al. 2010).

In environments such as river and lake edges, salt marshes and sand dunes, characterized by steep ecological gradients, the transect approach is considered as the most robust and cost-effective method for habitat monitoring (Stanisci et al. 2014; Prisco et al. 2016; Almeida et al. 2017). The transect method has been widely used to monitor the habitat conservation status (e.g. Ciccarelli 2014; Prisco et al. 2016; Šilc et al. 2016) in coastal dune systems, where factors such as wind intensity, nutrient availability and soil moisture change sharply from the coastline inlands (Maun 2009), thereby defining a complex mosaic of habitat types. Furthermore, the method has been recently recommended as the best tool to monitor the environmental and biotic heterogeneity in complex vegetation mosaics (Angelini et al. 2016; Gigante et al. 2016a).

For habitat monitoring, the most frequently used transects are line intercept transects, point intercept transects and, most commonly, belt transects (Hill et al. 2005). The belt transect approach consists in laying contiguous sampling plots (quadrats) of any size along the environmental gradient direction (Kent and Coker 1992). At each quadrat, plants are then identified and their abundance (normally percent cover) estimated. This method allows to explore the entire range of coastal plant communities (from the drift line to the fixed dune), to verify the distribution range of habitat types and the integrity of the coastal sequence, and to analyze the attributes (e.g. species richness and composition, spatial extent) of each community. Performed regularly (e.g. yearly), and compared over time, belt transects also guarantee an accurate identification of habitat trends (Angelini et al. 2016; Gigante et al. 2016a), both in spatial distribution and quality, the two main criteria used for assessing habitats conservation status (Keith et al. 2013; Bland et al. 2016; Gigante et al. 2016b; Janssen et al. 2016).

The belt transect approach is highly recommended for monitoring coastal dune habitat types, but its effectiveness is questionable when considering both the costs and the time needed for sampling. The environmental characteristics of the study area may require an increase in the sampling effort to obtain the same level of monitoring accuracy. These include the topography of the areas being sampled (e.g. size and complexity), the 
heterogeneity (i.e. amount of change) of the vegetation mosaic and the type of boundaries between vegetation types (distinct or not distinct). Plant communities of coastal systems are in fact closely related to dune morphologies which govern the abiotic features (e.g. water supply, grain size and salinity), thereby shaping various small-scale gradients and patterns along the dune system (Fenu et al. 2012; Bazzichetto et al. 2016; Silan et al. 2017). Thus, the complexity of the vegetation pattern and the amount of change along the sea-inland gradient increase with increasing dune morphology complexity. The complexity of the vegetation mosaic coupled with the width of the system (i.e. the number of quadrats to be surveyed) affect the time needed to perform the transect. Arguably, the time efficiency will be further dependent on quadrat size. For example, cover estimates are more difficult and time-consuming in large quadrats than in small quadrats and where plants are small and intermingled. Finally, the availability of field operators and their expertise in plant identification may dramatically influence the time needed to perform the assessment.

Since coastal systems are among the most threatened environments worldwide (Brown and McLachlan 2002; Del Vecchio et al. 2018; Gigante et al. 2018; Ivajnšič et al. 2018), it is critically important to find suitable monitoring methods which guarantee accurate data with a reasonable sampling effort. Several options can contribute to limit the sampling effort. Some authors analyzed the effect of changing plot number and/or plot size on the description of a community or a habitat type (Jonsson and Moen 1998; Dengler 2009). Other researchers suggested monitoring only some particular groups of species ("indicator species") considered as good descriptors of habitat identity and quality (Martínez Pastur et al. 2016; Del Vecchio et al. 2016). Finally, an alternative approach to reduce the sampling effort involves the preferential (i.e. by expert judgment) selection of homogeneous stands considered as representative of a particular habitat type, and the survey of a quadrat of appropriate size at each new vegetation type (Hill et al. 2005).

In the light of the several sampling options proposed so far, the aim of this work is to compare the completeness of datasets obtained by three different types of belt transect specifically designed to progressively reduce the sampling effort: (i) laying plots adjacently; consisting of frame quadrats laid contiguously along the beach-inland direction, this approach can be time-consuming if all the species are to be recorded and many quadrats are used, but provides very detailed data on vegetation; (ii) laying plots alternately, thereby halving the number of plots as well as the time needed for sampling; and (iii) laying plots according to a preferential survey design, i.e. recording a quadrat whenever a new plant community is found along the vegetation zonation, thereby strongly reducing both the number of plots per transect and the time needed to perform the sampling. Datasets completeness was evaluated in terms of number and type of habitats identified, spatial extent, species richness and composition, while the sampling effort was measured in terms of time needed for sampling.

\section{Methods}

\section{Study area}

The comparison of the effectiveness of monitoring methods was carried out along the North Adriatic coast (Italy), which represents the north-eastern part of the Mediterranean Basin. We selected one of the best preserved coastal dune sector, which is included in the Site of Community Importance IT3270017 "Delta del Po: tratto terminale e delta 
veneto" and in the Regional Park of the Po Delta, located in the southernmost part of the Venice lagoon. The coastal system is wider than $200 \mathrm{~m}$. Dunes are well developed, foredunes elevation ranges between 2 and $5.8 \mathrm{~m}$, while inland dune altitude reaches about $6 \mathrm{~m}$ (Simeoni et al. 2010). The vegetation sequence is complete (Caniglia 2007), ranging from pioneer annual communities on the beach to woody vegetation on fixed dunes (Table 1), thereby resembling the typical coastal zonation of Mediterranean coasts. Plant communities nomenclature in Table 1 follows specific literature (Buffa et al. 2007; Caniglia 2007; Gamper et al. 2008; Biondi et al. 2012; Sburlino et al. 2013).

\section{Coastal system sampling}

Coastal system sampling was performed in 2 consecutive days at the end of May (2017), which corresponds to the flowering period of the majority of coastal species in the North Adriatic region. Vegetation sampling was performed along two belt transects, laid perpendicularly to the coastline, walking twice along the same line. The transect location was selected in order to possibly include all the coastal communities along the vegetation zonation. Plant species together with their percentage cover were recorded in fixed-size plots, using the Braun-Blanquet scale (Westhoff and van der Maarel 1973; Dengler et al. 2008). We started from the edge of the Pine wood (at the beginning of the semi-fixed dune) and proceeded toward the seashore, until the vegetation of the drift line. In the first transect, "adjacent-plot transect", we sampled the vegetation in adjacent plots of $1 \mathrm{~m} \times 1 \mathrm{~m}$. The first plot of the transect was marked with poles and the beginning/end were georeferenced using a GPS unit. Afterwards, starting from the same point and following the same line, we sampled the vegetation in fewer larger plots, of $2 \mathrm{~m} \times 2 \mathrm{~m}$, a size considered as the most appropriate for describing coastal dune habitats (e.g. Acosta et al., 2007; Jucker et al. 2013). In this case, plots were located according to a preferential survey design, i.e. whenever a new plant community was found walking toward the coastline, following the vegetation zonation, "zonation-plot transect". In this case, the distance between the plots varied according to the vegetation changes. Thereafter, from the "adjacent-plot transect" we selected only the odd-numbered plots, to obtain an alternate sampling of the vegetation, "alternate-plot transect", with plots having a distance of $1 \mathrm{~m}$ from each others. Figure 1 represents the design of the three transect types.

\section{Data analyses}

Vegetation data were digitalized in Turboveg (Hennekens 1996) and converted from the Braun-Blanquet scale into percentages of the cover range, according to Hennekens (1996). From the adjacent-plot transect we obtained a matrix of 127 plots $\times 47$ species, from the alternate-plot transect a matrix of 64 plots $\times 47$ species, while from the zonation-plot transect a matrix of 8 plots $\times 39$ species. Species nomenclature follows Conti et al. (2005).

To verify the consistency of number and type of identified plant communities across the three types of transect we adopted the statistical approach normally used in vegetation science (e.g. Peet and Roberts 2013). To classify plots according to species composition, each species $\times$ plot matrix was analyzed through Detrended Correspondence Analysis (DCA, on species cover data; Pc-ord 5.1; McCune and Mefford 2006) and Cluster analysis (using average-linkage method and Bray-Curtis distance, on species cover data). The groups identified by multivariate analyses were then assigned to Natura 2000 habitat types (Annex I of the Habitat Directive 92/43/EEC), according to their 


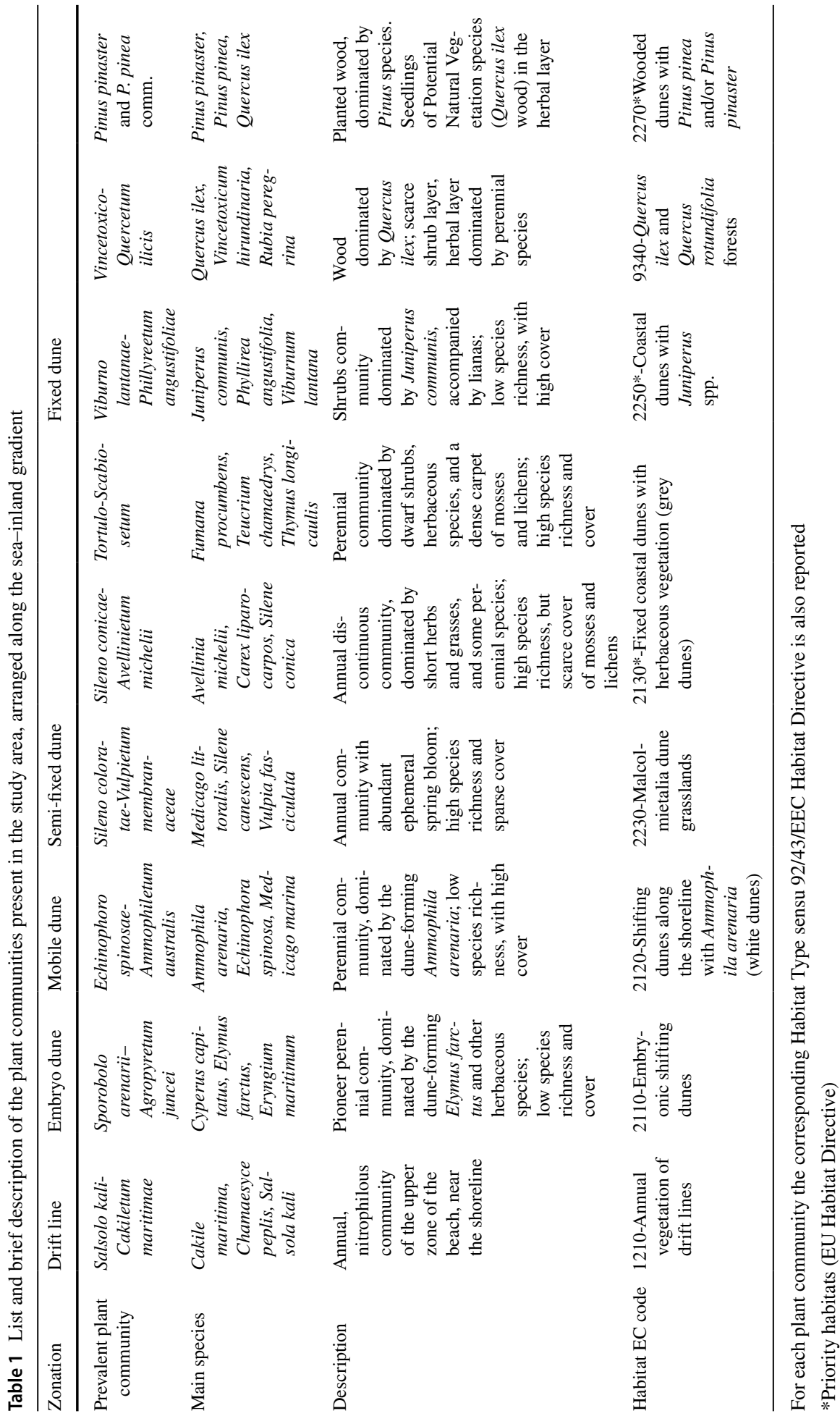




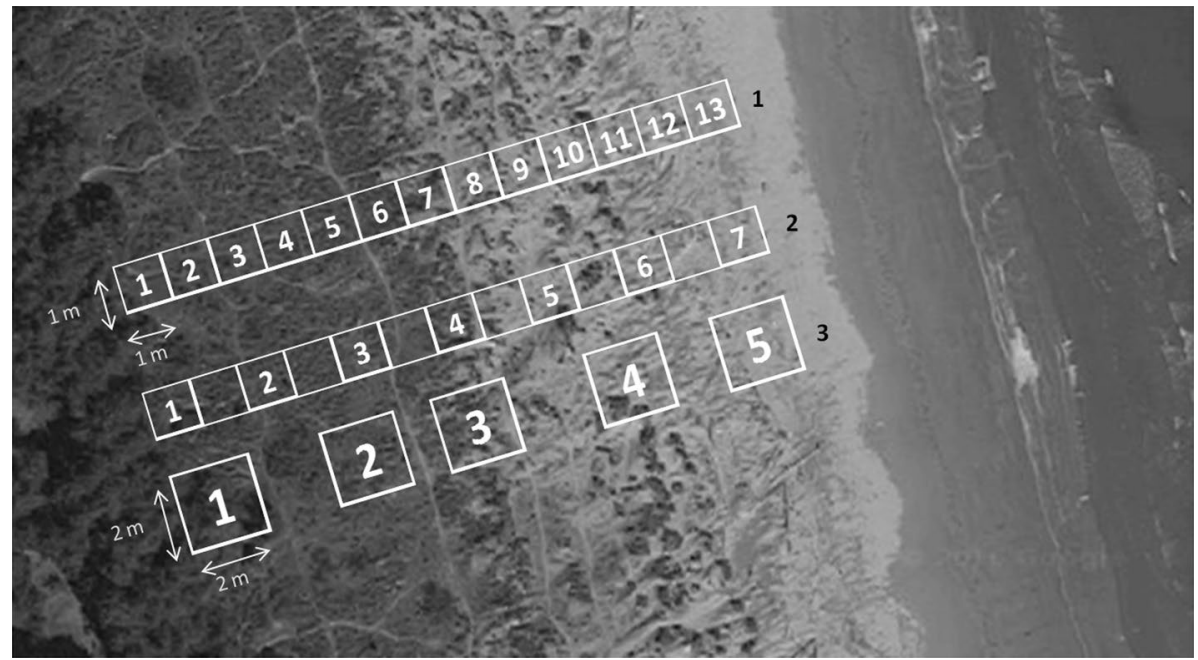

Fig. 1 Design of the three belt transect types used in the study. The picture is not to scale. $1=$ Adjacent-plot transect; $2=$ Alternate-plot transect; $3=$ Zonation-plot transect

diagnostic and dominant species, as listed in Biondi et al. (2009), European Commission (2013) and specific literature (Buffa et al. 2007; Gamper et al. 2008; Sburlino et al. 2008; Prisco et al. 2012; Sburlino et al. 2013).

To compare the accuracy and completeness of each monitoring method, we selected a list of variables to be measured based on the criteria established for assessing the risk of habitat collapse, that is a transformation of identity, a loss of defining features, and a replacement by a different ecosystem type (Keith et al. 2013), and the degree of endangerment (Janssen et al. 2016). The procedure involves the assessment of spatial symptoms (i.e. declining spatial distribution and/or spatial extent, and restricted spatial distribution) as well as functional symptoms (decline in quality due to either physical, abiotic degradation or the disruption of biotic interactions). Accordingly, we selected and measured a set of variables which are descriptors of habitat distribution range, spatial extent and quality. For each transect, we determined the number of habitat types recorded and the number of plots pertaining to each habitat type. Being performed along the sea-inland gradient, the transect method allows to evaluate the state of the entire dune system (i.e. the completeness of the typical plant communities zonation), to detect the presence of a habitat in a given location, thereby contributing to define its distribution range, and to identify the spatial extent of habitats. As descriptors of habitat quality, we calculated the following structural attributes: (i) mean total species cover per plot (\%), (ii) mean vascular species cover per plot (\%), (iii) mean moss layer cover per plot (\%), (iv) mean species richness per plot, and (v) the cumulative number of species recorded in each habitat.

To evaluate the "indicator species" approach, for each habitat we calculated the number of focal, generalist and alien species. Focal species, i.e. species that characterize the habitat type, were identified according to the aforementioned literature, used for the identification of habitat types. Alien species were identified according to Celesti-Grapow et al. (2010), while generalist species, i.e. all native opportunistic species not specific to dune environments, were identified on the basis of specific vegetation studies on coastal dunes (Del 
Vecchio et al. 2013, 2015, 2016). Finally, all the native species that were descriptors of dune habitats other than those identified, were classified as "other species".

Including all possible records that can be sampled in transects, we assumed the adjacent-plot transect as the most exhaustive sampling among the three chosen. Accordingly, results obtained through this method were assumed as a reference state of habitat types as well as of the coastal sequence, and used to evaluate the accuracy and completeness of the dataset provided by the alternate- and zonation-plot transects.

When possible (i.e. number of cases higher than 2), results were statistically compared by performing null models (Monte Carlo ANOVA). Within each habitat, we used the type of transect as grouping categorical variable, and the community attributes as dependent variables; the observed $\mathrm{F}$ index $\left(\mathrm{F}_{\mathrm{obs}}\right)$ was contrasted with those simulated by 1000 random permutations ( $\mathrm{F}_{\text {exp }}$; EcoSim 7.0; Gotelli and Entsminger 2001). For each habitat, the cumulative number of species as well as the number of indicator species were compared through rarefaction curves (Estimates 9; Colwell 2013).

For each transect we estimated the sampling effort in terms of time needed to perform the transect, considering that the team of field operators was composed of two expert researchers (one senior and one junior researcher) and one beginner.

\section{Results}

The number and type of habitats identified were consistent among the three transects (Table 2). For each transect, the multivariate analysis highlighted the same number of groups of plots and the same plant communities, arranged along the environmental gradient from the edge of the Pine wood to the drift line (Table 2; Fig. 2; technical results of multivariate analyses are provided as supplementary data in Online Resource 1). According to diagnostic and dominant species we identified five habitat types of EU Community interest (Table 2; Fig. 2). Two communities (dominated by Spartina versicolor and Helichrysum italicum respectively) were not recognized as Natura 2000 habitat types (Table 2). Species composition and cover for each community in each type of transect are summarized in Online Resource 2.

Based on the adjacent-plot transect, all habitats normally occupied a wide extent, and were represented by several plots, with a maximum of 28 for the habitat 2230, with the exception of the habitat 1210, typical of the drift line, which had a limited extent and was recorded only in 2 plots (Table 2 ).

All types of transects detected the presence of habitat types in the study site, thereby contributing to define their distribution range. The identification of the spatial extent of each habitat type was explicit and unambiguous only for the adjacent-plot transect (Table 2), while the alternate-plot transect allowed only an approximation of habitat spatial extension (at least $\pm 1 \mathrm{~m}$ at each border). The zonation-plot transect did not provide any spatial information and only allowed to detect the presence of a given habitat type.

The adjacent- and alternate-plot transects did not show significant differences in the structural attributes taken into account (total percentage cover per plot, vascular species cover per plot, moss layer cover per plot, species richness per plot), with the exception of the habitat 1210 (Table 2; Monte Carlo F test: $\mathrm{P}_{(\text {Fobs } \geq \text { Fexp) }}>0.05$ in any case). Conversely, the dataset provided by the zonation-plot transect showed differences in the absolute values of the majority of structural attributes, often overestimating the mean species richness and 
Biodiversity and Conservation

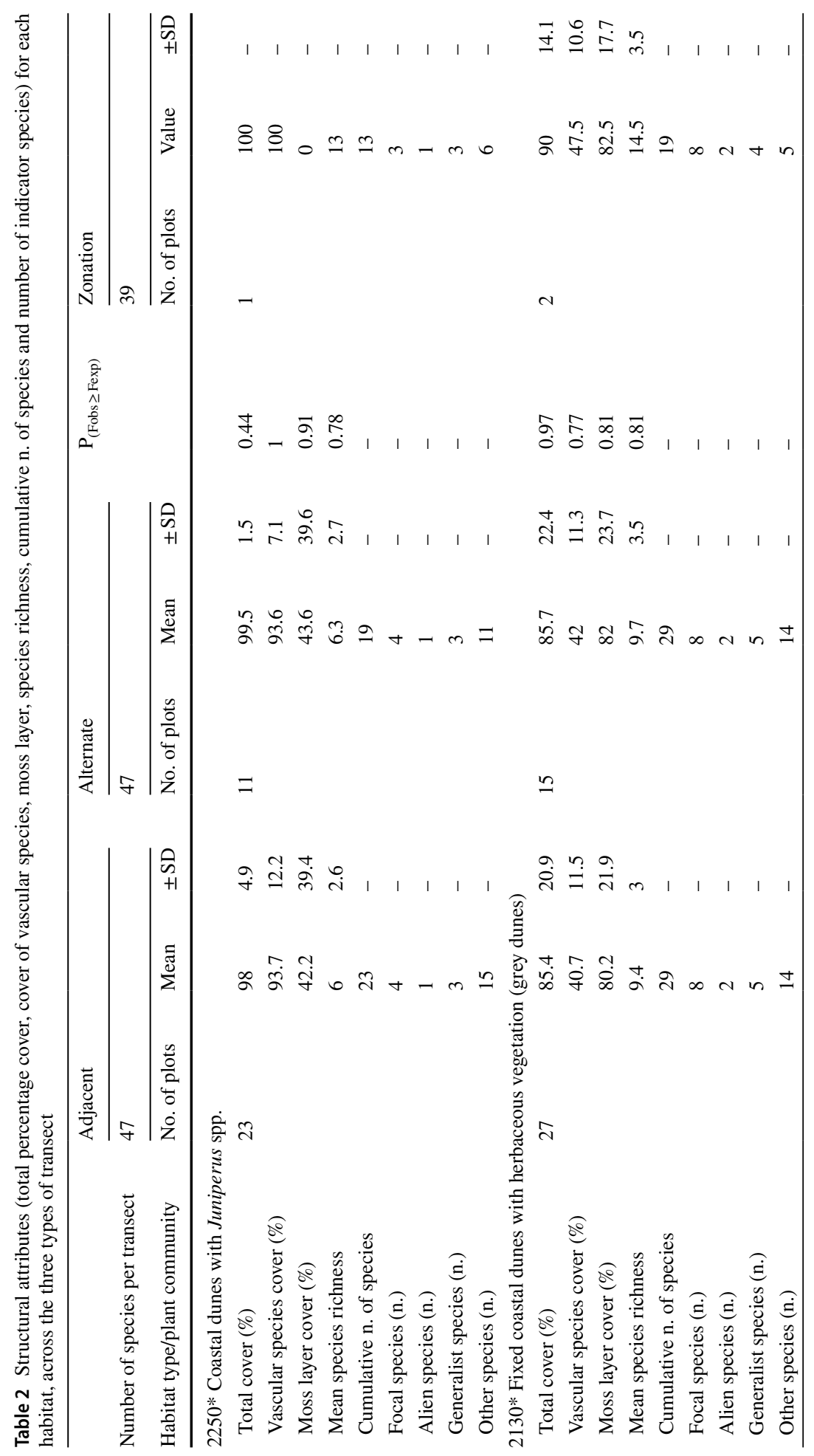

媳 Springer 


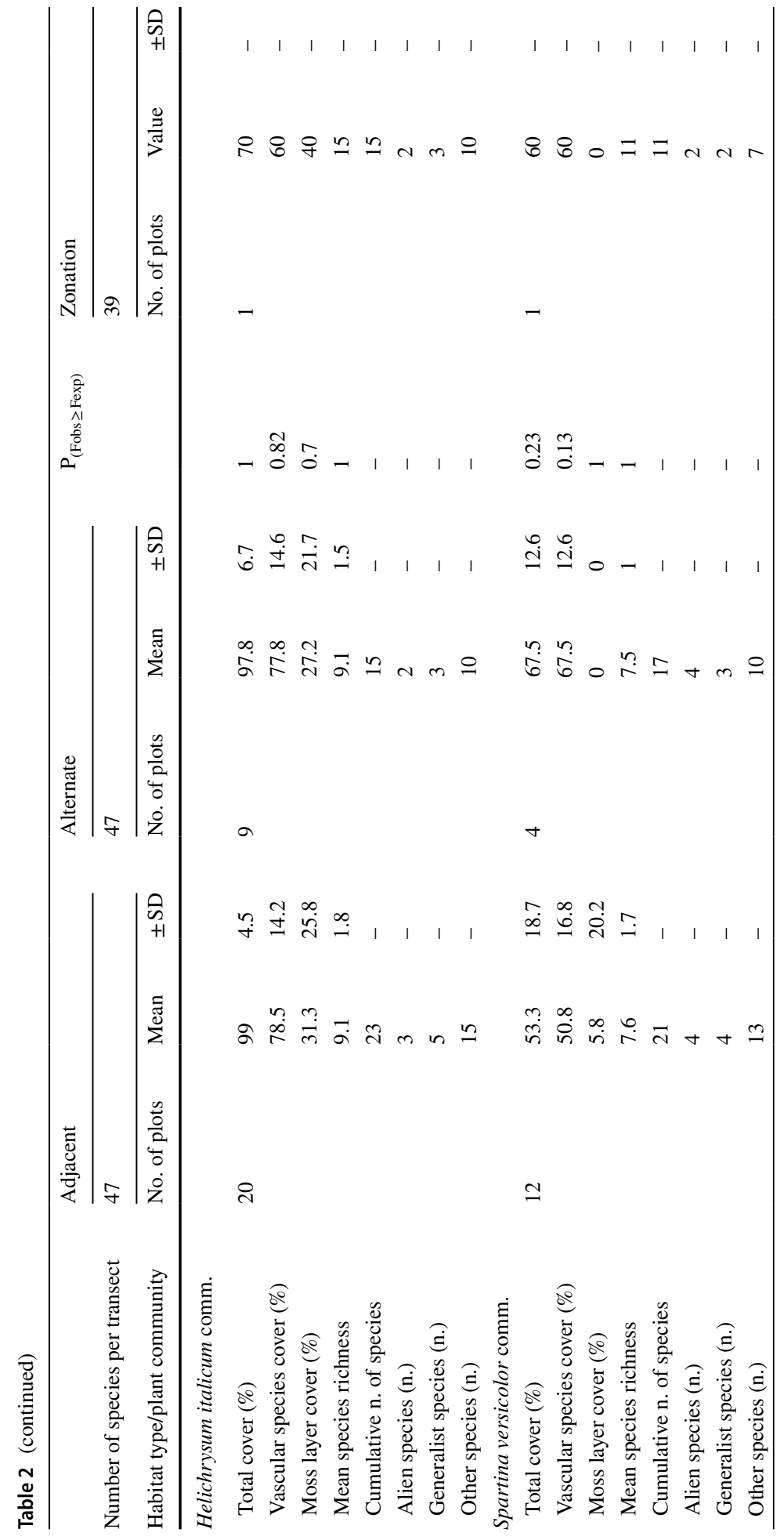


Biodiversity and Conservation

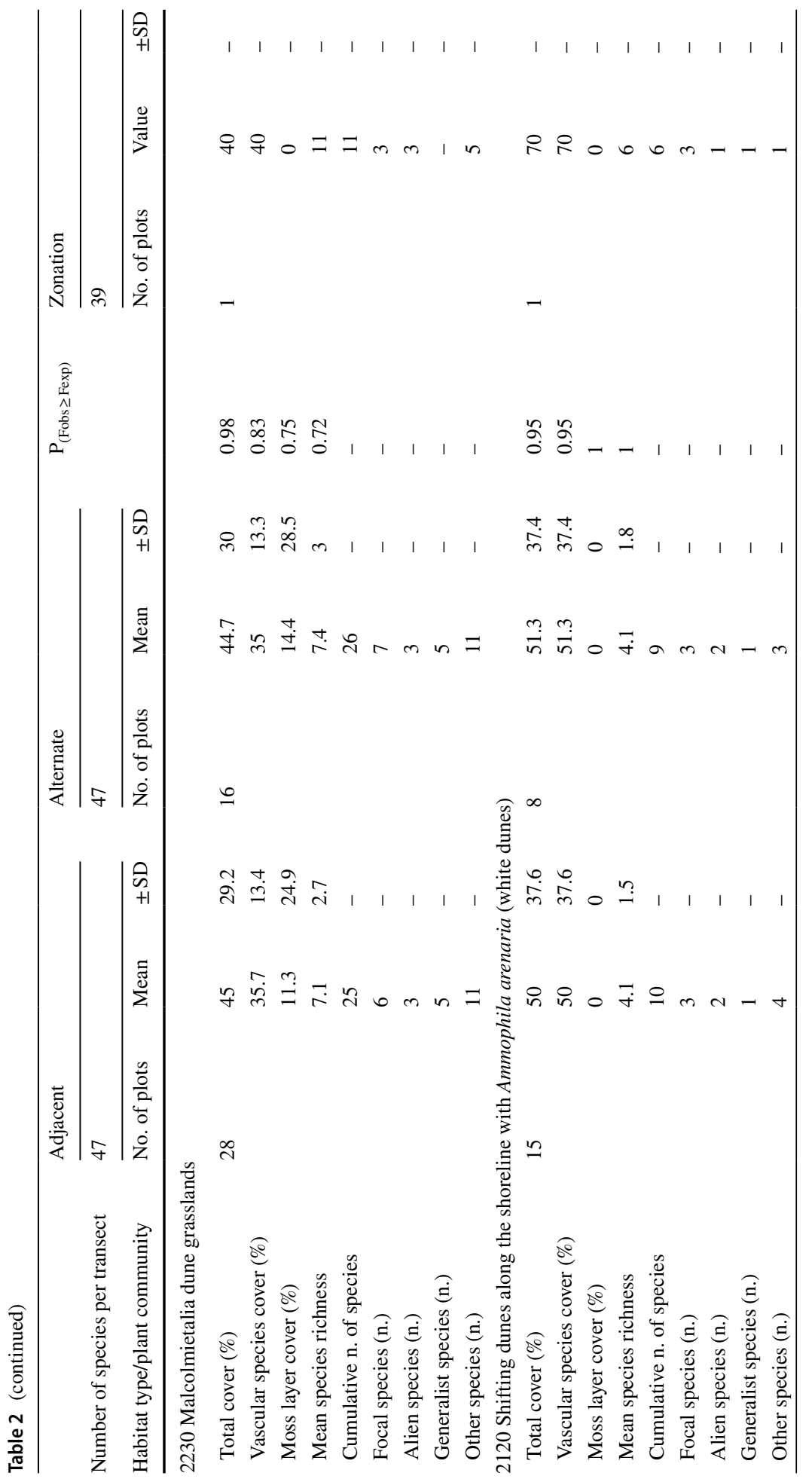

Springer 


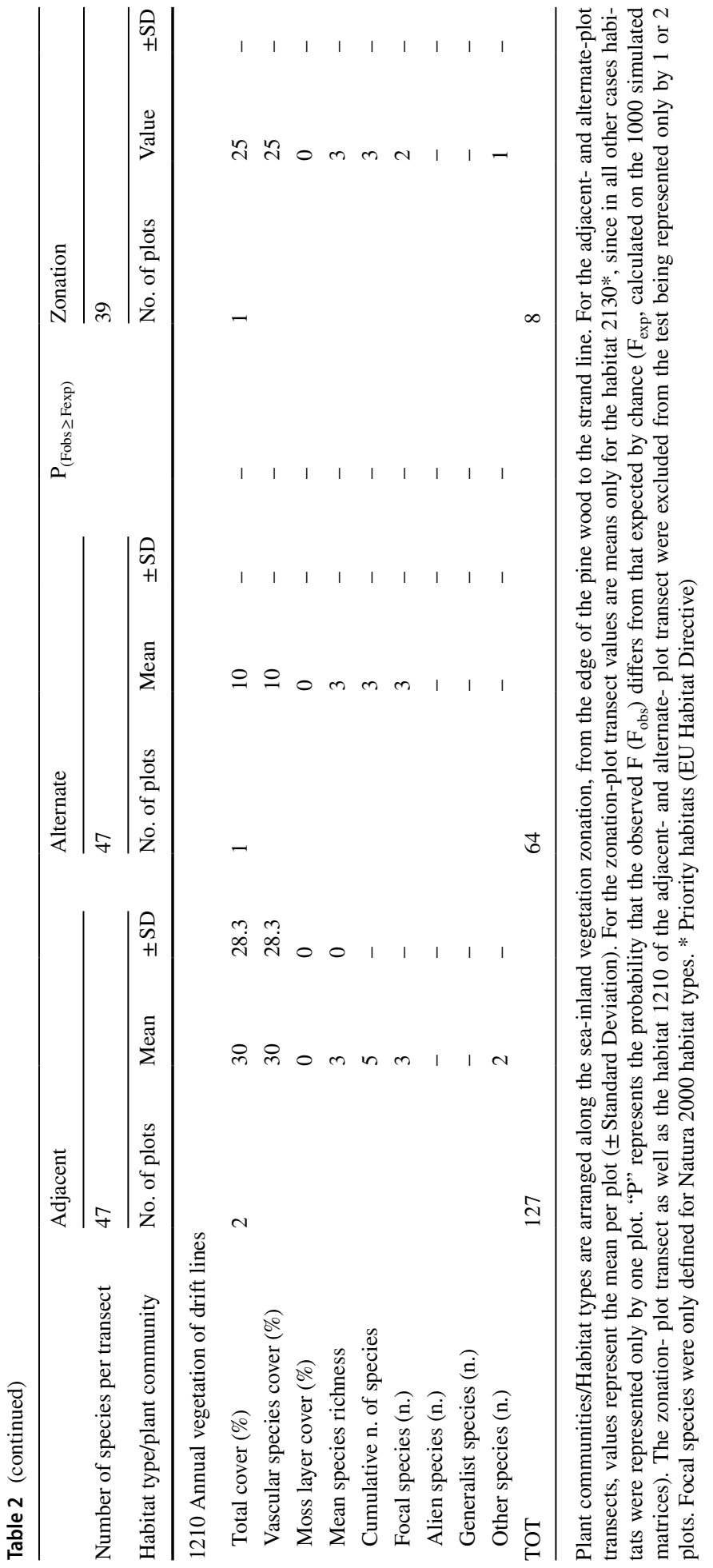


Adjacent-plot transect
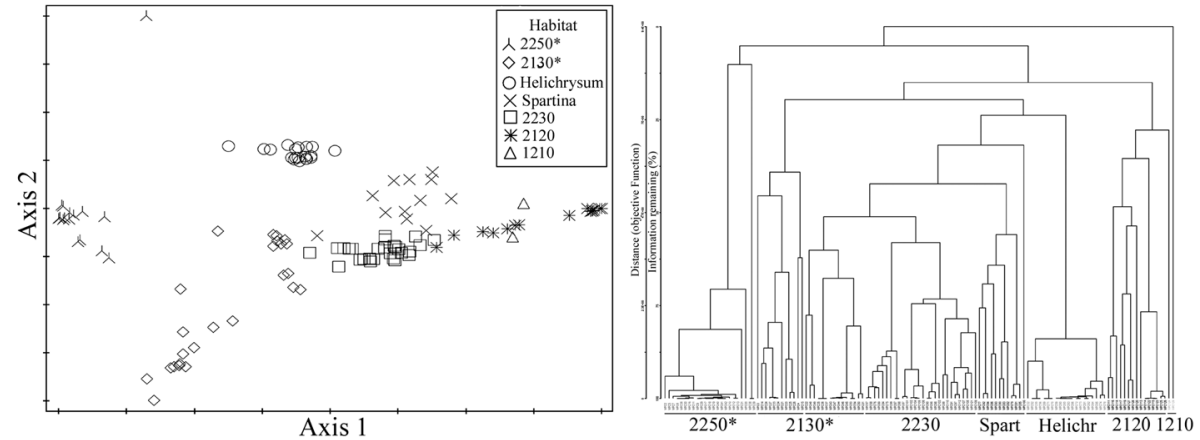

Alternate-plot transect
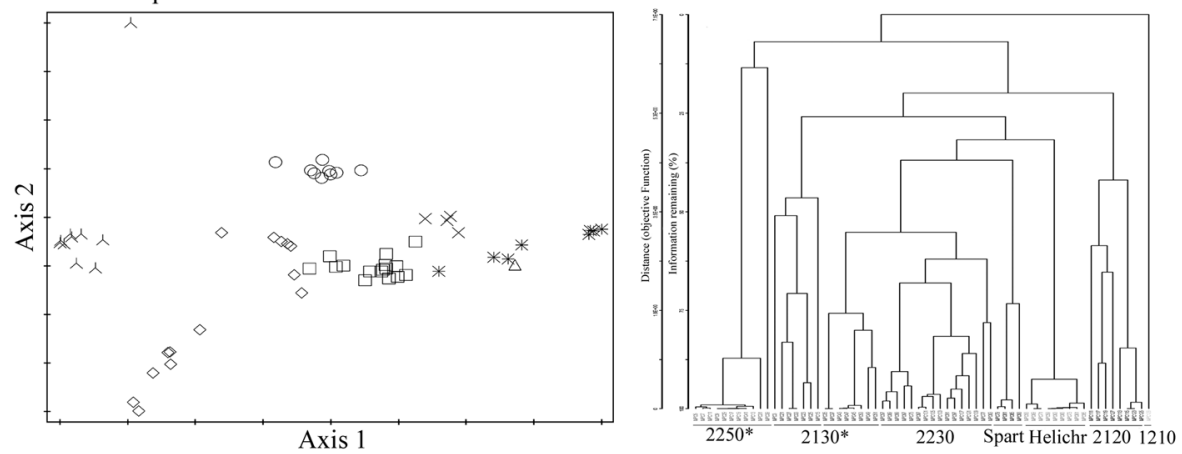

Zonation-plot transect
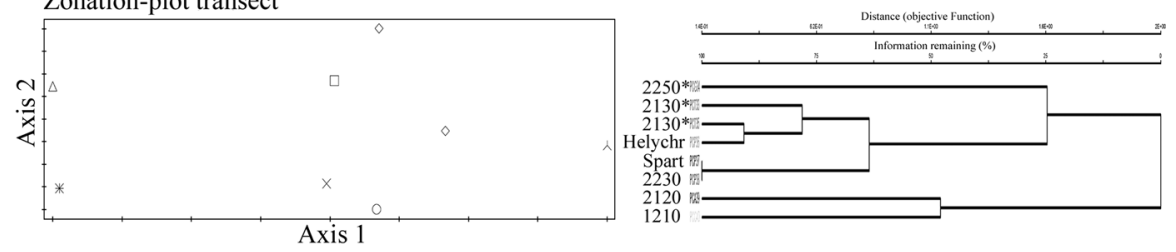

Fig. 2 Comparison of DCA scatter diagrams and cluster analysis dendrograms for the three types of transects

cover per plot, and underestimating the cover of the moss layer, although it was not possible to test the significance (Table 2; Online Resource 2).

Rarefaction curves showed that the cumulative number of species as well as the number of the indicator species detected by the adjacent- and alternate-plot transects were comparable, except for the habitat 1210 (Table 2; Fig. 3; rarefaction curves of the indicator species are provided in Online Resource 3). On the contrary, the zonation-plot transect detected a lower cumulative number of species for almost all of the habitat types. While the number of focal species was comparable, the number of the other indicator species groups was generally understimated (Table 2; Online Resource 2 and 3).

The sampling effort, measured as the time spent to perform the transect, greatly differed among the three types of transects. The adjacent-plot transect required the longest time to be completed, corresponding to 12 h, i.e. 2 working days, while the zonation-plot transect was performed in $3 \mathrm{~h}$. For the alternate plot transect we estimated 6-8 h (Table 3). 

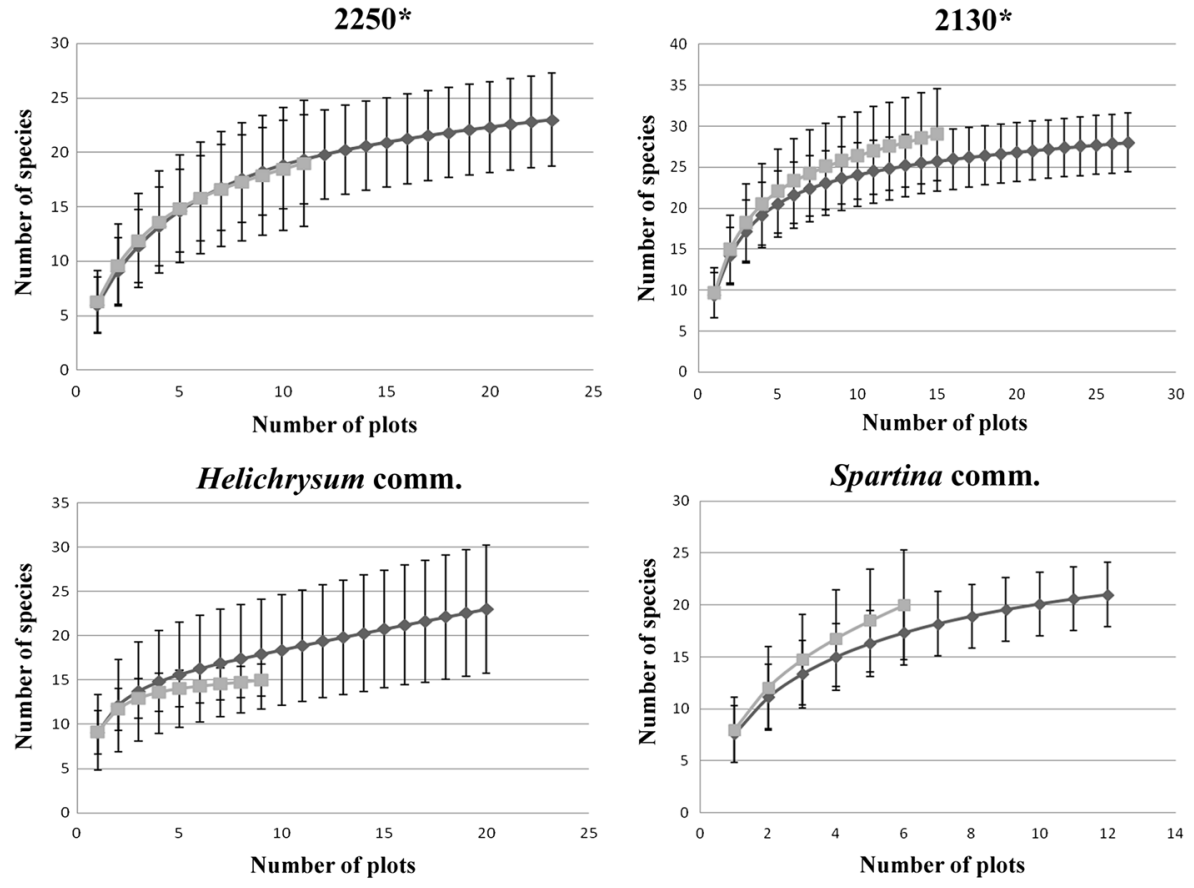

2230

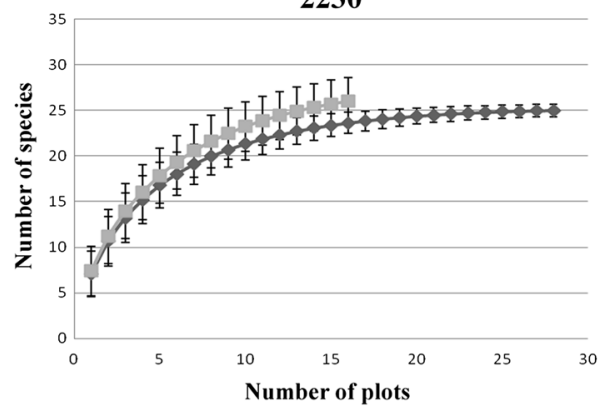

2120

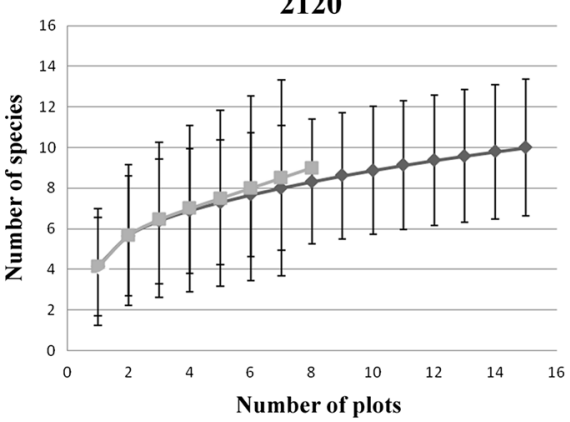

$\leadsto$ Adjacent - -Alternate

Fig. 3 Rarefaction curves of the cumulative number of species for each habitat, in the adjacent- and alternate-plot transect. Bars represent the $95 \%$ confidence interval. The zonation-plot transect, as well as the habitat 1210 are not shown

The sampling effort, measured in terms of time needed for sampling, progressively decreased from the adjacent-plot transect to the zonation-plot transect. Based on the trade-off between dataset completeness and time spent for surveying, the alternate-plot transect resulted the most effective sampling method. Indeed, despite a halved sampling effort, the method allowed the detection of habitat types presence, and provided complete information on species composition and the structural attributes considered, being the only weak point an imprecise detection of habitats spatial extent. 


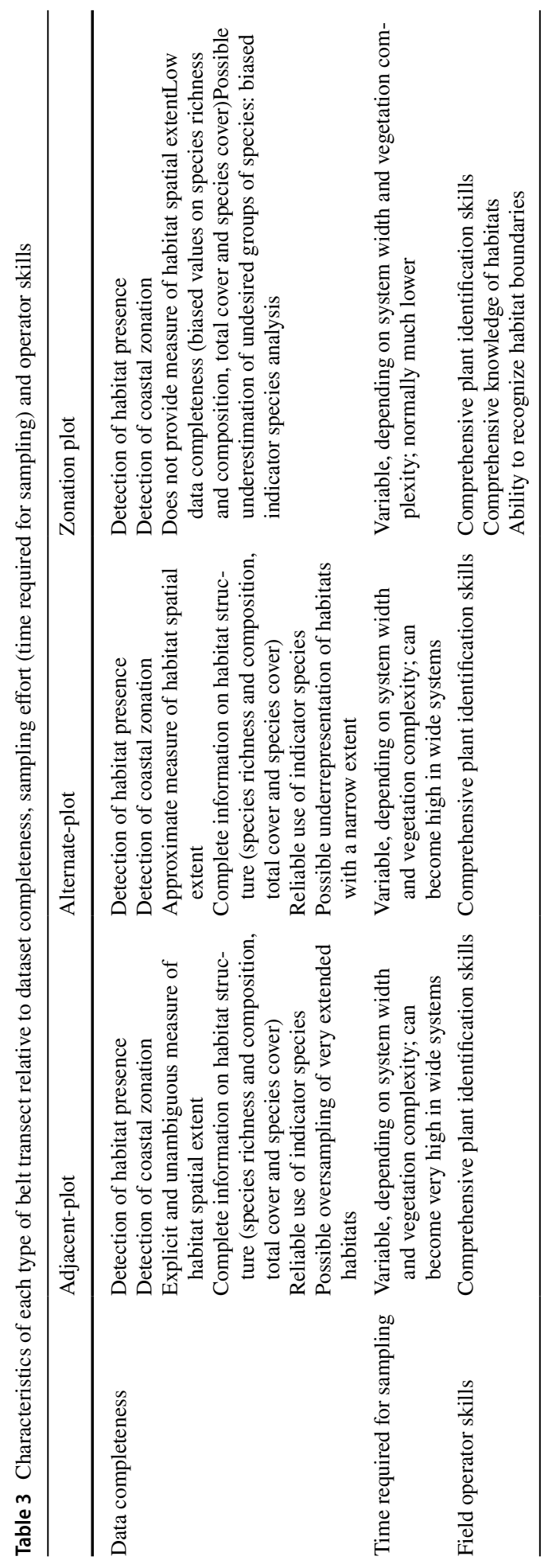




\section{Discussion}

The three methods were equally good in detecting the sequence of habitat types present along the sea-inland ecological gradient. This represents a key feature to assess the overall conservation status of coastal systems, since the lack of one habitat typically indicates disturbance, degradation, and habitat transformation or decline (Acosta et al. 2007; Buffa et al. 2007). Furthermore, the failure in detecting the presence of a given habitat type could lead to an incorrect definition of its distribution area, with consequences in the process of risk assessment, and possibly to overlook local extinctions (Janssen et al. 2016). However, habitat monitoring should also take into account the area shrinkage or decline and the negative effects of increasing habitat fragmentation (Keith et al. 2013). In this regard, only the adjacent-plot transect assured reliable estimates, allowing to precisely define the boundaries and the spatial extent of each habitat type in a given location, and to detect habitat regression or expansion when compared over time. On the contrary, the alternate-plot method provided an imperfect detection that would not be precisely comparable over time and might consistently produce biased values of habitat regression or expansion, while the zonation-plot transect did not involve any spatial measurement and could only give information on the presence/absence of a habitat type.

The three methods also differed in the description of each habitat type. Being comprehensive of all possible records that can be sampled in transects, the adjacent-plot transect provided the most complete dataset, i.e. the most precise representation of habitat types. The only remarkable drawback it evidenced concerned the time needed to perform the sampling, which largely drive the cost of a survey (Hill et al. 2005). The time needed to survey depends on several variables such as the morphological complexity of the area, its accessibility, the complexity of the vegetation mosaic and the skill of the field operator. However, in very complex and wide dune systems, where the most inland habitats can be found at a distance of $150 \mathrm{~m}$ or more from the coastline as in our case study, the application of traditional adjacent-plot transects can be limiting mostly due to the high number of quadrats to be recorded. When the vegetation sampling, performed by two experts and one beginner researcher exceeds $8 \mathrm{~h}$, the monitoring may become unsustainable. It is also worth considering the potential reduction in data quality associated with surveyor physical fatigue.

Despite the different number of plots surveyed and the different amount of time allocated to surveying, the alternate- and adjacent-plot transect provided comparable values of the structural attributes as well as of the indicator species detected, suggesting that the sample size (i.e. the number of plots), and the sampling effort, might be reduced without significantly losing information. Our results indicated that in well preserved coastal systems, where habitat types can extend for several meters, the reduction in the number of plots did not affect the representation of habitats, maintaining comparable values of mean species richness, cumulative number of species as well as the number of the indicator species detected. Our findings are consistent with those of Mikulyuk et al. (2010), who stated that a higher sampling effort does not always result in an increase in data accuracy and completeness. Indeed, different results emerged only in the comparison of habitats with a narrow extent, represented by a low number of plots (e.g. the habitat 1210 which belt was only $2 \mathrm{~m}$ wide). In this case, reducing an already low number of plots potentially affects the outcome. Thus, when habitat types have a narrow extent, either naturally or following disturbance events, the alternate-plot transect should be avoided. 
The zonation-plot transect was the most effective in reducing the sampling time. However, the presence of at least one expert field operator, able to recognize boundaries between different plant communities in the field and to lay the plot in the point that best represented the characteristics of the community was compulsory to perform the transect. Thus, while for the adjacent- and alternate-plot transects surveyors should be competent field botanists, able to identify the species in the field, performing a zonation-plot transect requires comprehensive plant identification skills, comprehensive knowledge of habitats and the ability to recognize habitat boundaries. The involvement of such field operators may represent a limit, since it can be expensive thus increasing the costs of monitoring (Carpaneto et al. 2017). Moreover, the extreme reduction in the number of plots per habitat type resulted in a loss of data accuracy and completeness. The relationship between the number of replicates and the completeness of information is wellknown in data analysis (e.g. Rocchini et al. 2017), and this pattern clearly emerged from our results. Although placed in the most representative location of the community, one single plot proved to be inadequate to thoroughly describe the features of the habitat types (e.g. species richness and cover, cumulative number of species). Furthermore, the enlargement of the plot size did not assure data completeness and was not enough to retrieve information lost due to the reduced number of plots.

The zonation-plot transect also was less precise in detecting the indicator species groups. Arguably, this is mainly due to the subjective plot selection by the field operator: choosing the location that best represents the plant community, undesired groups of species, such as generalists or aliens, have less chance to be included in the survey, due to the tendency to avoid disturbed communities (Swacha et al. 2017). In monitoring programs requiring minimal error and maximum accuracy, all the groups of species should be reliably detected, because habitat degradation, or the shifting toward different habitats due to the increase of other species, can be detected by a decline in focal species, with generalist, alien and other species remaining constant, or vice versa, by an increase in these groups of species, with focal species remaining constant (Biondi et al. 2012; Del Vecchio et al. 2016; Sperandii et al. 2018). This represents a major shortcoming of this method when applied to monitoring, unless plots represent permanent sampling locations and sufficient samples are taken to maximize the representativeness.

In summary, although the zonation-plot transect had the lowest sampling effort, it provided only an approximation of the state of the dunal communities, and the accuracy was low. The alternate-plot transect showed the best trade-off between the sampling effort, in terms of time spent for surveying, and the completeness of information obtained.

Selecting the most appropriate method is an important step in any monitoring plan. To maximise the efficient use of monitoring resources the most cost-effective method appropriate to the monitoring objective should be used. The results emerged from our study can support the selection of the best sampling procedure according to monitoring objective, field conditions, available resources and personnel, and can be applied to other coastal systems.

On the basis of our research, we suggest the following best practices to set monitoring programs: (1) use the adjacent-plot transect, whenever it is possible; however, in case of wide and complex coastal system where the field survey might exceed $8 \mathrm{~h}$, the implementation of alternative sampling methods might be taken into consideration; (2) use the alternate-plot transect as a first choice alternative to the adjacent-plot transect, being aware of its weakness in case of habitats with limited spatial extent; (3) if the sampling effort has to be extremely reduced (e.g. due to resource constrains), the zonation-plot transect can be 
used as well, with the caution of involving at least one expert field operator, and possibly performing more than one plot for each plant community.

\section{References}

Acosta A, Ercole S, Stanisci A, Pillar VDP, Blasi C (2007) Coastal vegetation zonation and dune morphology in some Mediterranean ecosystems. J Coast Res 23:1518-1524

Almeida D, Alcaraz-Hernandez JD, Merciai R, Benejam L, Garcia-Berthou E (2017) Relationship of fish indices with sampling effort and land use change in a large Mediterranean river. Sci Total Environ 605:1055-1063

Angelini P, Casella L, Grignetti A, Genovesi P (2016) Manuali per il monitoraggio di specie e habitat di interesse comunitario (Direttiva 92/43/CEE) in Italia: habitat. ISPRA, Serie Manuali e linee guida, $142 / 2016$

Bazzichetto M, Malavasi M, Acosta A, Carranza ML (2016) How does dune morphology shape coastal EC habitats occurrence? A remote sensing approach using airborne LiDAR on the Mediterranean coast. Ecol Indic 71:618-626

Biondi E, Blasi C, Burrascano S, Casavecchia S, Copiz R, Del Vico E, Galdenzi D, et al. (2009) Italian interpretation manual of the 92/43/EEC directive habitats. http://vnr.unipg.it/habitat/. Accessed 1 March 2017. Società Botanica Italiana. Ministero dell'Ambiente e della tutela del territorio e del mare, D.P.N

Biondi E, Casavecchia S, Pesaresi S (2012) Nitrophilous and ruderal species as indicators of climate change. Case study from the Italian Adriatic coast. Plant Biosyst 146:134-142

Bland LM, Keith DA, Miller RM, Murray NJ, Rodríguez JP (2016) Guidelines for the application of IUCN Red List of ecosystems categories and criteria, Version 1.1. IUCN, Gland Switzerland

Brown AC, McLachlan A (2002) Sandy shore ecosystems and the threats facing them: some predictions for the year 2025. Environ Conserv 29(1):62-77

Buffa G, Filesi L, Gamper U, Sburlino G (2007) Qualità e grado di conservazione del paesaggio vegetale del litorale sabbioso del Veneto (Italia settentrionale). Fitosociologia 44:49-58

Caniglia G (2007) Stato attuale dei litorali del veneto. Fitosociologia 44:59-65

Carpaneto GM, Campanaro A, Hardersen S, Audisio P, Bologna MA, Roversi PF, Peverieri GS et al (2017) The LIFE Project "Monitoring of insects with public participation" (MIPP): aims, methods and conclusions. Nat Conserv 20:1-35

Celesti-Grapow L, Pretto F, Carli E, Blasi C (2010) Flora vascolare alloctona e invasiva delle regioni d'Italia. Casa Editrice Università La Sapienza, Roma

Ciccarelli D (2014) Mediterranean coastal sand dune vegetation: influence of natural and anthropogenic factors. Environ Manage 54:194-204

Colwell R K (2013). EstimateS: statistical estimation of species richness and shared species from samples. Version 9. User's Guide and application published at: http://purl.oclc.org/estimates. Accessed $1 \mathrm{March}$ 2018

Commission European (2013) Interpretation manual of European Union habitats-EUR28. European Commission DG Environment, Brussels

Conn PB, Moreland EE, Regehr EV, Richmond EL, Cameron MF, Boveng PL (2016) Using simulation to evaluate wildlife survey designs: polar bears and seals in the Chukchi Sea. R Soc Open Sci 3:150-561

Conti F, Abbate G, Alessandrini A, Blasi C (2005) An annotated checklist of the Italian vascular flora. Palombi Editori, Roma

Del Vecchio S, Acosta A, Stanisci A (2013) The impact of Acacia saligna invasion on Italian coastal dune EC habitats. C R Biol 336:364-369

Del Vecchio S, Pizzo L, Buffa G (2015) The response of plant community diversity to alien invasion: evidence from a sand dune time series. Biodivers Conserv 24:371-392

Del Vecchio S, Slaviero A, Fantinato E, Buffa G (2016) The use of plant community attributes to detect habitat quality in coastal environments. AoB Plants. https://doi.org/10.1093/aobpla/plw040

Del Vecchio S, Fantinato E, Janssen JAM, Bioret F, Acosta A, Prisco I, Tzonev R, Marcenò C, Rodwell J, Buffa G (2018) Biogeographic variability of coastal perennial grasslands at the European scale. Appl Veg Sci 21:312-321

Dengler J (2009) Which function describes the species-area relationship best? A review and empirical evaluation. J Biogeogr 36:728-744

Dengler J, Chytrý M, Ewald J (2008) Phytosociology. In: Jørgensen SE, Fath BD (eds) Encyclopedia of ecology. Elsevier, Oxford, pp 2767-2779 
Evans D, Arvela M (2011) Assessment and reporting under the habitats directive. European Topic Centre on Biological Diversity, Paris

Fenu G, Carboni M, Acosta A, Bacchetta G (2012) Environmental factors influencing coastal vegetation pattern: new insights from the Mediterranean basin. Folia Geobot 48:493-508

Gamper U, Filesi L, Buffa G, Sburlino G (2008) Diversità fitocenotica delle dune costiere nordadriatiche 1-Le comunità fanerofitiche. Fitosociologia 45:3-21

Geri F, La Porta N, Zottele F, Ciolli M (2016) Mapping historical data: recovering a forgotten floristic and vegetation database for biodiversity monitoring. Isprs Int Geo-Inf 5:100

Gigante D, Attorre F, Venanzoni R et al (2016a) A methodological protocol for Annex I Habitats monitoring: the contribution of vegetation science. Plant Sociol 53:77-78

Gigante D, Foggi B, Venanzoni R, Viciani D, Buffa G (2016b) Habitats on the grid: the spatial dimension does matter for red-listing. J Nat Conserv 32:1-9

Gigante D, Acosta ATR, Agrillo E, Armiraglio S, Assini S, Attorre F, Bagella S, Buffa G, Casella L, Giancola C, Giusso del Galdo GP, Marcenò C, Pezzi G, Prisco I, Venanzoni R, Viciani D (2018) Habitat conservation in Italy: the state of the art in the light of the first European Red List of Terrestrial and Freshwater Habitats. Rend Fis Acc Lincei 29:251-265

Gotelli NJ, Entsminger GL (2001) EcoSim: null models software for ecology. Version 7. Jericho, VT, Acquired Intelligence Inc. \& Kesey-Bear. http://garyentsminger.com/ecosim/index.htm. Accessed 1 February 2018

Henle K, Bauch B, Auliya M, Kuelvik M, Pe'er G, Schmeller DS, Framstad E (2013) Priorities for biodiversity monitoring in Europe: a review of supranational policies and a novel scheme for integrative prioritization. Ecol Indic 33:5-18

Hennekens SM (1996) TURBO(VEG). Software package for input, processing, and presentation of phytosociological data. IBN-DLO Wageningen, NL and University of Lancaster, UK

Hill D, Fasham M, Tucker G, Shewry M, Shaw P (eds) (2005) Handbook of biodiversity methods, survey, evaluation and monitoring. Cambridge University Press, Cambridge

Hughes BB, Beas-Luna R, Barner AK, Brewitt K, Brumbaugh DR, Cerny-Chipman EB, Close SL et al (2017) Long-term studies contribute disproportionately to ecology and policy. Bioscience 67:271-281

Ivajnšič D, Kaligarič M, Fantinato E, Del Vecchio S, Buffa G (2018) The fate of coastal habitats in the Venice Lagoon from the sea level rise perspective. Appl Geogr 98:34-42

Janssen J, Rodwell J, García Criado M, Gubbay S, Haynes T, Nieto A, Sanders N et al (2016) European Red List of Habitats. European Union, Luxembourg

Jonsson BG, Moen J (1998) Patterns in species associations in plant communities: the importance of scale. J Veg Sci 9:327-332

Jucker T, Carboni M, Acosta A (2013) Going beyond taxonomic diversity: deconstructing biodiversity patterns reveals the true cost of iceplant invasion. Divers Distrib 19:1566-1577

Keith DA, Rodríguez JP, Rodríguez-Clark KM, Nicholson E, Aapala K, Alonso A, Asmussen M et al (2013) Scientific foundations for an IUCN Red List of ecosystems. PLoS ONE 8:1-25

Kent M, Coker P (1992) Vegetation description and analyses. A practical approach. Belhaven Press, London

Lindenmayer DB, Likens GE (2010) The science and application of ecological monitoring. Biol Conserv 143:1317-1328

Lovett GM, Burns DA, Driscoll CT, Jenkins JC, Mitchell MJ, Rustad L, Shanley JB et al (2007) Who needs environmental monitoring? Front Ecol Environ 5:253-260

Martínez Pastur G, Peri PL, Soler RM, Schindler S, Lencinas MV (2016) Biodiversity potential of Nothofagus forests in tierra del fuego (argentina): tool proposal for regional conservation planning. Biodivers Conserv 25:1843-1862

Maun MA (2009) The biology of coastal sandy dunes. Oxford University Press, Oxford

McCune B, Mefford MJ (2006) PC-ORD multivariate analysis of ecological data. Version 5. Gleneden Beach, MjM Software, Oregon

McDonald-Madden E, Baxter PWJ, Fuller RA, Martin TG, Game ET, Montambault J, Possingham HP (2010) Monitoring does not always count. Trends Ecol Evol 25:547-550

Meyer C, Weigelt P, Kreft H (2016) Multidimensional biases, gaps and uncertainties in global plant occurrence information. Ecol Lett 19:992-1006

Mikulyuk A, Hauxwell J, Rasmussen P, Knight S, Wagner KI, Nault ME, Ridgely D (2010) Testing a methodology for assessing plant communities in temperate inland lakes. Lake Reserv Manage 26:54-62

Peet RK, Roberts DW (2013) Classification of natural and semi-natural vegetation. In: van der Maarel E, Franklin J (eds) Vegetation ecology, 2nd edn. Oxford University Press, New York, pp 28-70

Prisco I, Acosta A, Ercole S (2012) An overview of the Italian coastal dune EU habitats. Ann Bot 2:39-48 
Prisco I, Stanisci A, Acosta A (2016) Mediterranean dunes on the go: evidence from a short term study on coastal herbaceous vegetation. Estuar Coast Shelf Sci 182:40-46

Rocchini D, Garzon-Lopez CX, Marcantonio M, Amici V, Bacaro G, Bastin L, Brummitt N et al (2017) Anticipating species distributions: handling sampling effort bias under a Bayesian framework. Sci Total Environ 584:282-290

Sburlino G, Buffa G, Filesi L, Gamper U (2008) Phytocoenotic originality of the N-Adriatic coastal sand dunes (Northern Italy) in the European context: the Stipa veneta-rich communities. Plant Biosyst 142:533-539

Sburlino G, Buffa G, Filesi L, Gamper U, Ghirelli L (2013) Phytocoenotic diversity of the N-Adriatic coastal sand dunes - the herbaceous communities of the fixed dunes and the vegetation of the interdunal wetlands. Plant Sociol 50:57-77

Silan G, Del Vecchio S, Fantinato E, Buffa G (2017) Habitat quality assessment through a multifaceted approach: the case of the habitat 2130* in Italy. Plant Sociol 54:13-22

Šilc U, Stevanović ZD, Ibraliu A, Luković M, Stešević D (2016) Human impact on sandy beach vegetation along the southeastern Adriatic coast. Biologia 71:865-874

Simeoni U, Valpreda E, Corbau C (2010) A national database on coastal dunes: Emilia-Romagna and southern Veneto littorals (Italy). In: Green D (ed) Coastal and marine geospatial technologies. Springer, Dordrecht, pp 87-96

Sperandii MG, Prisco I, Acosta A (2018) Hard times for italian coastal dunes: insights from a diachronic analysis based on random plots. Biodivers Conserv 27:633-646

Stanisci A, Acosta A, Carranza M, De Chiro M, Del Vecchio S, Di Martino L, Frattaroli A et al (2014) EU habitats monitoring along the coastal dunes of the LTER sites of Abruzzo and Molise (Italy). Plant Sociol 51:51-56

Swacha G, Botta-Dukat Z, Kacki Z, Pruchniewicz D, Zolnierz L (2017) A performance comparison of sampling methods in the assessment of species composition patterns and environment-vegetation relationships in species-rich grasslands. Acta Soc Bot Pol 86:15

Westhoff V, van der Maarel E (1973) The Braun-Blanquet approach. In: Whittaker RH (ed) Handbook of vegetation science, part 5, Classification and ordination of communities. Dr. W. Junk, The Hague, pp $617-726$ 